kow (aLa pura locura de los políticosm), Gazetn Wyborcza, 18 de julio de 1992.

" Bronislaw Gercmek, aCivil Society Then and Nown, Joumal of Democracy (1992), vol. 3, 2. Vhase tambićn su articulo "Die Civil Society gegen den Kommunismus: Polens Botschafts, en K. Michalski (Hrsg.), Eiropa und die Civi Society (Stuttgart, 1991).

* R. Sharlet, wuman Rights and Civil Society". en W. Griffith (ed), Eastem Europ: The Opening Curtain? (San Francisco/Londres: Westview. 1989).

* Jose Casanova, «Kosciol wobec wyboru" ( La Iglesia frente a una elecionn), Res Publica (1991), 9:10.

3 Jadwiga Staniszkis, The Dynamics of the Breakthrough in Eastm Europe: The Polish Experience (Berkeley-Los Angeles-Oxford, 1991), p. 26.

" Maciej Potepa, "Rewolucja, spoleczenstwo obywatelskic, demokracja» ("Revolución, sociedad civil y democracia»), en Tadeusz Buksinski (cd.), Filozofia w dobie przemian (La flosofia en un periodo de tronsformaciones) (Poznan, 1994), p. 262.

"Vid. Krzysztof Wrzesinski, "Panstwo i prawo a spolezenstwo obywatelskie* ( El Estado, el derecho y la sociedad civils), Studia filozoficzne (1090), 4, y tambièn Janina Zakrzewska, «Prawu w spoleczenstwie obywatelskim» ("El derecho en la sociedaxl civil»), en Obywatel Odrodzerit, cit. pp. 107-112.

if Vit. Maciej Potepa, op. cil, p. 263, y Tadeusz Buksinski, Apoleczenstwo obywatelskie spoleczenstwo tynkowe" ( $\mathrm{L}$ a sociedad civil y la sociedad de mercados), en Filosofa w doble premian. cit., p. 284.

to Jozet Tischner, Eyka Solidamosci oraz Homo Sovieticus (Cracovia, 1992); Aleksander Smolar, "Vom Homo Sovicticus zum Burgurs, Trantit (1993), 3.

* Lena Kolarkka-Bobinska. Aspirations, Vakes and Interests. Poland 1989-9f (Varsovia: IFIS Publishers, 1994).

27 Más información de interés sobre la idea de sociedad civil en Polonia y en la Europa del Exte se encontrará en Jerzy Szacki, *Eín neues I and? Traum und Wirklichkeit der polnischen Demokraticn, Transit (1990), 3; Jcrzy Szacki, Liberalizm po komunizmie (El liberatisno después del comunismo) (Cracovia, 1994), pp. 90-145; Zbigniew Pescrynsk, "Solidarity and the Rebirth of Civil Sociely in Poland», en John Keanc (cd.), Civit Socery and the State. New European Perspectives (Londres, 1988); Zhignicw Rau (ed.), The Ree mergence of Citil Society in Eastern Europe and the Sovier Union (Boulder: Westview Press, 1991).

\title{
Participación, ciudadanía y democracia: ¿hacia el tercer sistema?
}

\author{
ROBERTO R. GUERRA \\ Universidad de La Laguna
}

La hegemonia de una concepción de la política, tan cínica como instrumental y elitista, unida a las insuficiencias y promesas incumplidas de las democracias reales, ha empezado a generar en las sociedades occidentales desarrolladas cierto pesimismo sobre el futuro de la forma de gobierno democrático. No debe sorprendernos por tanto que junto a los acríticos festejos por el triunfo de la democracia liberal asistamos desce hace algunos años a la percepción de su paradójica crisis. Buena parte de la teoría política actual tiende así a mostrarse profundamente preocupada no sólo por la tendencia de amplios sectores ciu- dadanos a asociar la política y la democracia con comportamientos y actitudes ligadas a la corrupción, la mentira y el clientelismo, sino también por fenómenos como el reducido margen de participación que permiten los sistemas democráticos imperantes, o la progresiva pérdida de afiliación de los partidos políticos y su cyidente agotamiento como instrumentos de mediación entre el ciudadano y el estado. En un panorama tan preocupante, en el que la política y la democracia parecen haberse divorciado definitivamente de la participación y acción política ciudadana, la publicación de una obra como la de 
Tomás R. Villasante (Las democracias participativas. De la participación ciudadana a las alternativas de sociedad, Madrid, Ediciones HOAC, 1995) constituye un alentador intento de poncr de relieve que en el interior de las democracias liberales actuales existen ya ciertas experiencias, métodos y prácticas de participación que, a pesar de sus problemas y carácter minoritario, mucho pueden aportar a la hora de averiguar cómo podemos construir democracias participativas y altemativas de sociedad. La obra aporta un amplio abanico de descripciones, reflexiones y sugerencias sobre las que aqui no puedo extenderme. Entre ellas destaca el csfucrzo por mostrar, a través del análisis de diferentes experiencias concretas, no sólo que la participación política de la ciudadanía «es posible hoy cuando hay voluntad política para ello», sino también que, a pesar de los interesados discursos sobre la apatía e indiferencia de los ciudadanos, «a la gente le interesa realmente participar». Sobresale además cicrta preocupación por reflexionar criticamente sobre csas mismas experiencias (electorales y participativas), sobre los métodos (planificación, descentralización, desburocratización) y sobre las prácicas (municipales). Descuella también la asunción de una perspectiva metodológica que se niega a reducir la enorme complejidad y diversidad de las sociedades contemporáneas, a simplificar las múltiples asociaciones, movimicntos e iniciativas que realmente la dinamizan. En suma, una perspectiva la suya que tiene bien presente tanto la riqueza y las potencialidades de la vida asociativa como la constatación de que más que uniformes los caminos democráticos son plurales. Por contra, se adivina cierta alergia a la teorización, motivada tal vez por una comprensible desconfianza hacia la complacencia academicista que con frecuencia nos rodea.

\section{Participación y asociacionismo}

Frente a la ceguera de quienes ven en los partidos, las elecciones y los representantes políticos los únicos cauces de participación, de legitimidad y de iniciativa, Villasante nos propone volver la mirada hacia el campo de potencialidades que ofrecen las formas alternativas de participación y organización social propias de la multiplicidad de movimicntos y asociaciones vecinales, juveniles, artísticas, pacifistas, étnicas, feministas, culturales, ecologistas, recreativas, etcétera, presentes en las sociedades democráticas actuales. En oposición a los mínimos y rígidos cauces de participación que brindan las democracias establecidas (Aranguren, 1979), los movimientos sociales y las asociaciones de ciudadanos ${ }^{\prime}$ han sido capaces de adoptar en la práctica una amplia variedad de formas de participación y acción política que desbordan abiertamente las fronteras institucionales del sistcma político. La gran mayoría de movimientos y asociaciones poseen modelos de organización interna que permiten una participación libre, cotidiana y directa de la ciudadanía, así como que ésta entable interacciones sencillas, personalizadas $y$ horizontales.

Además la propia variedad de estos movimientos y asociaciones ofrece la posibilidad de dar cauce a la multiplicidad de intereses ciudadanos, esto es, de abrir las puertas a las diferencias inherentcs a la riqueza y diversidad de la propia sociedad. Al mismo tiempo, su no-gubernamentalidad e independencia del poder estatal (al menos en teoría) las constituye en instituciones autónomas capaces de actuar como "escuclas de democracia" en las que el autodesarrollo individual, la autodeterminación cívica y el espíritu critico son clementos centrales de su devenir. Finalmente, su carácter de asociaciones «sin ánimo de lucros hace posible otra manera de entender y ejercer la participación política, 
es decir, una forma de participación no centrada en la persecución de intereses privados o corporativos sino, por el contrario, en la autoorganización y puesta en marcha de iniciativas locales que afectan a la globalidad de la sociedad. El asociacionismo ciudadano y sus redes de acciôn constituye asi para Villasante un tercer sector o tercer sistema ${ }^{2}$ que puede actuar como complemento crítico frente a los sistemas del estado y la cconomía. Pero es también un espacio de potencialidades donde los movimientos y asociaciones pueden dar rienda suelta a sus propósitos y proyectos para el ensayo de nucvas experiencias económicas, politicas y culturales. Una tierra donde, según se nos dice, se están incubando diferentes experiencias de control democrático, de cconomías sociales y de amovidas» culturales, que se han de ir generalizando, que han de enfrentarse con la lógica dominante de la tecnoestructura corporativa, y que por lo lanto no lo tienen nada fácil (276).

\section{Pluralismo emancipatorio $y$ asociacionismo critico}

Las sugerencias de Villasante entroncan abiertamente con las recientes reflexiones sobre el pluralismo emancipatorio desde C. B. Macpherson (1977 y 1985) a J.R. CapeIla (1993) o sobre el asociacionismo crítico desde J. Keane (1988) a M. Walzer (1991), como posibles vías de salida a la parálisis y problemas de las democracias representativas de final de siglo. Se trata, desde unas y otras perspectivas, de volver la vista hacia el vasto ámbito social constituido por las redes horizontales de asociación y acción en las que los ciudadanos pueden ejercer y desarrollar activamente sus potencialidades individuales, sus plurales concepciones de la vida buena y sus alternativas de sociedad. Estas asociaciones voluntarias, a pesar de sus diversos intereses y fines, desempeñan - como ya seña- laba Tocqueville (1835) y como reconocieron hace algunas decadas $G$. Almond y $S$. Verba $(1963,265)$ - un decisivo rol dentro de la cultura política democrática en tanto que es bastante probable que el individuo asociado tienda «a considerarse más competente como ciudadano, a ser un participante más activo en la política, a conoccr y preocuparse más de los asuntos políticos. Está, por consiguiente, más cerca del modelo ideal de ciudadano democrático».

La virtud del asociacionismo estaría constituida por el hecho de que permite imaginar en términos no contractualistas el surgimiento espontáneo de relaciones libres de dominación (J. Habermas, 1993, 47). De esta manera, «ya no será necesario concebir a la sociedad libre de dominación como un orden instrumental $y$, por ende, prepolítico, que se establece por contratos, es decir, por acuerdos interesados entre particulares que actúan impulsados por la búsqueda de su propio éxito. Una sociedad integrada por asociaciones en lugar de mercados representaria según indica J. Habermas - un orden que, pese a ser político, estaría exento de dominación».

Es cierto, como muchos reconocen, que el proyecto de una sociedad integrada por una serie de redes horizontales de asociaciones voluntarias ${ }^{3}$ tropieza hoy dia con multitud de obstáculos. Entre ellos descuellan aquellos que 1. Habermas considera derivados de las necesidades de dirección y organización de las sociedades modernas. Porque no podemos ignorar el escaso peso que el sistcma político actual asigna a cstas asociaciones, ni tampoco sus realmente reducidas capacidades de presión e influencia sobre la toma de decisiones políticas y económicas. Sin cmbargo, no por ello dejan de representar un reto al orden politico cstablecido ( $R$. J. Dalton y $M$. Kucchler, 1990). En especial debido a que dicho de nuevo en palabras de J. Habermas - tales asociaciones no sólo pueden colaborar de forma decisiva en la forma- 
ción autónoma y discursiva de la opinión y la voluntad pública $(1993,51$ y s5.). Pueden también, a través de la deliberación pública y la acción política, difundir convicciones prácticas, poner de relieve asuntos importantes para la sociedad, aportar posibles soluciones a los problemas sociales, descubrir valores, generar buenas razones, modificar actitudes, etcétera, que surtan efcctos, al menos a medio plazo, sobre el poder político establecido.

Repensar la democracia desde el pluralismo emancipatorio y el asociacionismo critico podrian suponer así la posibilidad tanto de avanzar hacia modelos participa* tivos de democracia como de recuperar una ciudadanía activa atenta al estado y la acción gubemamental, pero comprometida también con múltiples asociaciones capaces de actuar de manera autónoma y solidaria. Una ciudadanía que, a pesar de que a menudo se abstenga de afiliarse a uno u otro partido político, participa de hecho en movimientos y asociaciones cuya actividad tiene claras repercusiones sobre la opinión pública y la toma de decisiones gubemamentales, además de ser capaz -como aduce Villasante- de promover valores y modelos alternativos de sociedad.

Desde esta perspectiva, el asociacionismo no significaria, ni mucho menos, un abandono de la política ". Sería, por el contrario, una decisiva contribución al intento de alcanzar modelos más plurales y satisfactorios de democracia en tanto que proporcionaría otras formas y cauces de participación, incorporando nuevos sujetos del quehacer político y nuevos ambitos e instituciones democráticas en las cuales una participación política más plena de los ciudadanos podría ser posible. Fs más, proporcionaría tal vez una nueva forma de hacer politica que, alejada del cinismo, instrumentalismo y elitismo políticos imperantes, estaría mucho más preocupada por el autodesarrollo individual y la acción deliberada, democrática y solidaria en el devenir colectivo.

\section{Sociedad civil y tercer sistema}

La importancia de los movimientos sociales y del asociacionismo para la construcción de sociedades más democráticas no ha pasado, ni mucho menos, desapercibida para la teoría política actual. Existe ya una amplia y conocida bibliografia al respecto que no parece necesario mencionar aquí. Lo que pretendo en lo que sigue es más bien relacionar las sugerencias de Villasante sobre los movimientos sociales y el asociacionismo ciudadano con algunos intentos de recuperar y redefinir la noción de sociedad civil. De hecho, a pesar de sus reticencias hacia dicha noción, comparte preocupaciones comunes con algunos de los autores de esos intentos.

La redefinición de la sociedad civil constituye, para buena parte de la teoria política reciente, una posible vía de solución a las crecientes patologías de las sociedades occidentales (desarrollismo económico, contaminación ambiental, racismo, drogadicción, etcétera). Tal perspectiva parece orientada por la constatación de que los acuciantes problemas sociales mencionados no pueden encontrar una solución adecuada sin una participación responsable y solidaria de la ciudadanía. Pero también por la necesidad de encontrar, ante la soledad del ciudadano frente al estado y la creciente burocratización y oligarquización de las gigantescas organizaciones políticas y económicas que nos rodean, un espacio de asociación y una trama de relaciones humanas sin coerción en la que los ciudadanos, si así lo desean, pueden participar en condiciones de libertad (M. Walzer, 1991,31). El objetivo es, en suma, fomentar una mayor participación política de la ciudadanía y alcanzar un ámbito de relaciones 
humanas on el que sea posible recuperar la sociabilidad perdida en unas sociedades dominadas por relaciones sociales profundamente jerarquizadas y anónimas. La sociedad civil es reconceptualizada así como parte destacada de la vertiente no-institucional de ese ámbito puiblico ${ }^{5}$ en el que los ciudadanos expresan, discuten y actualizan diferentes versiones del interés público (V. Pérez-Díaz, 1993, 80). Denotaría, pues, una esfera de acción política que, pese a su carácter contradictorio ${ }^{6}$, incluiría a aquellas prácticas de comunicación, rituales discursivos y tribunas públicas, en que actores colectivos disputan sobre la unidad y futuro de la sociedad (H. Dubiel, 1994, 118). Designaría además una esfera pública autónoma que constituiría una precondición para la praxis de la autodeterminación civica y que podría generar un poder comunicativo capaz de ejercer cierto grado de control e influencia sobre el poder administrativo (J. Habermas, 1994, 2 y 9; cf. tambićn 1993). La sociedad civil es pensada pues como un ámbito desde cl cual los individuos pueden alcanzar tanto un amplio grado de influencia sobre la opinión pública como cierto control y presión política sobre la actividad estatal o gubernamental. Actuaria así como «una espina clavada permancntemente en el flanco del poder políticom (J. Keane, 1988, 35) $y$, en csa misma medida aunque no sin dificultades e insuficiencias, como constante desafío al poder del estado, sus institucioncs y representantes.

Pero, al mismo tiempo, la sociedad civil, en tanto que conjunto de asociaciones ciudadanas, es concebida también como un dominio en el que se dan «solidaridades concretas y auténticas» (M. Walzer, 1991. 34), esto es, como un marco social en el que una multitud de personas se asocian, comunican, solidarizan y ayudan efectivamente entre si. Constituye de esta forma una esfera de relaciones humanas en la que sería posible la cooperación, la soli- daridad y la fraternidad entre individuos y colectivos, así como la revitalización de una vida asociativa y activa en condiciones de libertad e igualdad.

Es por todo esto por lo que la pretensión de buena parte de estos esfuerzos de revitalización de la sociedad civil quizá puedan ser resumidos como un intento de asumir la rousseaniana aspiración de «aproximar cuanto podamos al hombre y al ciudadano, cuyo soporte es siempre el individuo, pero cuidando de invertir el sentido de dicha aproximación [...] puesto que el objetivo a perseguir no scría ya estatalizar a la sociedad civil sino, por así decirlo, sociocivilizar al Estadom (J. Muguerza, 1995, 19 y ss.).

Las sugerencias esbozadas mucho tienen en común con la perspeciva de Villasante. Sin cmbargo, éste no duda en señalar que muchos «toman "sociedad" en un sentido tan amplio que les cabe todo con tal de que sea contra el Estado». Y no le faltan razoncs para apuntarlo, pues incluso algunas de las concepciones de la sociedad civil más alejadas de las pretensiones ncoliberales de «retorno al mercado» la definen como una esfera no estatal que incluye unidades productivas y domésticas, a la vez que organizaciones de ayuda mutua y servicios comunitarios privatizados (J. Keane, 1988, 33). El problema radicaría en que tales concepciones de la sociedad civil son demasiado inclusivas en cierto sentido y, por ende, excluyentes en otro. Esto es: designan un marco social de referencia para las actividades de los movimientos sociales y las asociaciones ciudadanas mediante una noción que incluye también a todas aquellas asociaciones y grupos de presión que siendo completamente independientes del estado, en modo alguno los son de la economía, «Sociedad civil» es la noción que, designando una esfera social de la que forman parte los movimientos y asociaciones de carácter alternativo, tambićn incluye a todas aquellas organizaciones o grupos económicos y de lucro que 
no poseen formas participativas de demo cracia ni están dispuestos a cuestionar los valores egoistas imperantes. La red de asociaciones ciudadanas no sería así, al menos cn su totalidad, independiente de las exigencias del sistema económico y de la racionalidad instrumental que le es propia. Una tan amplia inclusión termina por favorecer el principio desigualitarista de exclu. sión contra el que apuntan todas las experiencias presentadas y analizadas por Villa* sante.

Son éstas las razones básicas por las que el autot de Las democracias participativas sugiere modificar nuestro esquema conceptual y adoptar la noción de «tercer sistema», como sistema del Ciudadano que se opone al sistema del Príncipe (estatal) y al sistema del Mercader (económico). Con ella quiere designar un espacio social en el que se desarrolla la actividad de movimientos, asociaciones y redes de acción social de carácter voluntario, no-lucrativo y no-gubernamental. Porque la idea de tercer sistema - tal como aduce Villasantepretende designar un campo social específico: un espacio, el de la ciudadania, que apunta "a un profundo cambio de valoress, que propone «un método democrático instituyente», y que mira por tanto ahacia unas "alternativas de sociedad", hacia un cambio civilizatorio». Y es que el principal valor de las experiencias ciudadanas exploradas quizá resida en que, cn las prácticas y métodos que han puesto en marcha, ya se estén dando pequeños pero importantes pasos en pro de ese «cambio civilizatorio». En tal sentido no puede dejar de reconocerse que fraccionadamente van apareciendo «alternativas de sociedad», en aquellas grietas que se le escapan al actual sistema, sumido como está en diversas crisis que se entrecruzan (económica, ecológica, demográfica, de valores, etcétera), como sugiere Villasante con un lenguaje que recuerda a Foucault. En concreto: «Económicamente se inician experiencias basa- das en el valor de uso frente al valor de cambio; políticamente las legitimidades democráticas se están replanteando y empieza a haber experiencias de democracias participativas; culturalmente son otros los valores antipatriarcales, pacifistas, ecologistas, solidarios que cultivan los nucvos movimientos sociales» (289). Asi las cosas, frente la supucsta ascpsia do cicrtos usos de la noción de sociedad civil, la idea de «tercer sistema» incorporaría los aspectos de la crítica política, económica, cultural y ética que cierto asociacionismo ciudadano está realizando ya frente al modelo de sociedad en que nos encontramos inmersos.

Sin embargo, tampoco la débil conceptualización que propone Villasante está exenta de problemas. En su acierto parece estar su insuficiencia. Sin ir más lejos la propia de idea de «sistema» puede indicar que existe cierta homogeneidad y cohesión (que realmente no existe) entre la multiplicidad de movimientos sociales y asociaciones ciudadanas de perfil crítico. Con ello se corre el doble riesgo de no atender a la realidad del movimiento asociativo $y$ de anular una de sus más enriquecedoras cualidades: su pluralidad y diversidad de formas, objetivos, etcétera. Por otro lado, parece sugerir que existe cierta heterogeneidad e incongruencia entre el «tercer sistema» y cl "primer» y "segundo" sistemas, que son los que conformarían la «socicdad burguesa» que está en cl origen de la idea de «sociedad civil» ahora repensada. $\mathrm{Se}$ postula así una dualización (en realidad una tripartición) del sistema social que resulta trivial por su apriorismo. Llama solución alternativa al problema estándar.

A pesar de todo la construcción de una sociedad participativa y plural, de una sociedad de ciudalanos activos sin relacionos de dominación u opresión y de ma esfera de relaciones interpersonales solidarias de tipo comunitario puede seguir constituyendo un ideal que, a pesar de su carác- 
ter utópico, es capaz de orientar nuestra acción política real, precisamente por su carácter pragmático. En tal sentido conviene tener presente la importancia que para una idea alternativa de la democracia realmente existente tiene la capacidad de innovación política y crítica cultural que poseen los inquietos movimientos sociales y el perseverante asociacionismo ciudadano. Cierto, por asi decirlo, que no todo cl monte es orégano. Es posible $-\mathrm{y}$ de hecho así ocurre, como no podía ser menos - que en muchas de estas asociaciones se pongan en juego visiones e intereses aldeanos, particularistas o corporativistas. Pero, sin duda, de su enorme capacidad para sorprender y desbordar las rutinas de la sociedad y de la democracia establecida mucho podemos aprender sobre la democratización efectiva y la construcción de democracias más participadas. Sólo que para ello se requiere «una nueva sensibilidad para lo local, específico y contingente $-\mathrm{y}$, sobre todo, un nuevo reconocimicnto (parafraseando una célebre máxima) - de que la vida digna se encuentra [también] en los pequeños detalles» (M. Walzer, 1991, 39). En todo caso, tanto éste como muchos otros persistentes e imaginativos esfuerzos en favor de una democracia plenamente pluralista (C. B. Macpherson, 1985; R. Dahl, 1989; J. Keane, 1988), deliberativa (J. Habermas, 1993 y 1994; S. Benhabib, 1994) y participativa (C. Pateman, 1970; C. B. Macpherson, 1977; D. Held, 1987) apuntan hacia otras formas de entender y vivir un idcal azaroso pero con veinticinco siglos de historia. Pero también hacia otras concepciones alternativas de la política, de lo político y de los políticos. $Y$ acaso este último sea un problema al que las reflexiones sobre la participación, la ciudadanía y la democracia deban prestarle mucha mayor atención?

\section{REFERENCIAS}

ALMOND, G. y Verra, S. (1963): The Civic Culture: Political Attitudes and Democracy in Five Nations, Princeton, Princeton University Press.

ARANGUREN, J. L. (1979): La democracia establecida. Una critica intelectual, Madrid, Taurus.

Ascol, U. (1987): «Estado de Biencstar y Acción voluntaria», en REIS, 38: $119-162$.

BENHABIB, S. (1994): «Deliberative Rationality and Models of Democratic Legitimacy», en Constellations, $1,1: 26-52$.

CAPELLA, J. R. (1993): Los ciudadanos siervos, Madrid, Trotta.

COHEN, J., y Rogers, J. (1992): «Secondary associations and democratic governments", en Politics and Society, $4: 393-472$.

DAHL, R. (1989): Democracy and Its Critics, Now Haven, Yale University Press.

DALTON, R. J., y KUECM.ER, M. (comps.) (1990): Los nuevos movimientos sociales: Un reto al orden político, Valencia, Alfons cl Magnànim, 1992.

Dubiel, H. (1994): «Metamorfosis de la sociedad civil. Autolimitación y modernización reflexiva», en Debats, 50: 108-123.

GIDRON, B.; KRAMER, R. M., y SALAMON, L. M. (1992): Government and the Third Sector, San Francisco, I.B. Publisher.

GINER, S. (1987): Ensayos civiles, Barcelona, Península.

Giner, S., y SARASA, S. (1995): «Altruismo y politica social», en Leviatún, 61: 67-98.

HABERMAS, J. (1993): «La soberanía popular como procedimiento. Un concepto normativo de lo público», en HERRERA, M. (coord.): Jürgen Habermas: moralidad, ética y política. Propuestas críticas, Madrid, Alianza, pp. 27-58.

(1994), «Three Normative Models of Democracym, en Constellations, 1, 1: 1-10. 
HELD, D. (1987): Models of Democracy, Cambridge, Polity Press.

KEANE, J. (1988): Democracia y sociedad civil, Madrid, Alianza, 1992.

KRAMER, R. M. (1981): Voluntan Agencies in the Welfare State, Berkeley, University of California Press.

KuHnif, S., y Sfil.F, P. (eds.) (1992): Govemment and Voluntay Organizations, Aldershot, Avebury.

MACPHER5ON, C. B. (1977): The Life and Times of Liberal Democracy, Oxford, Oxford University Press.

- (1985): The Rise and Fall of Economic Iustice and Other Essays, Oxford, Oxford University Press.

MuguerzA, J. (1995): El individuo ante la ética pública, inédito.

NERFIN, M. (1988): Ni principe, ni mercader: ciudadano, Lima, Socialismo y Participación.

- (1994): «Los movimientos sociales y otro desarrollos, en Cuademos de la Red CIMS, 2.

OFFE, C. (1988): Partidos políticos y nuevos movimientos sociales, Madrid, Sistema.
- (1992): La gestión política, Madrid, MTSS.

PATEMAN, C. (1970): Participation and Democratic Theory, Cambridge, Cambridge University Press.

Pérez-Díaz, V. (1993): La primacía de la sociedad civil, Madrid, Alianza.

RIECHMANN, J., y FERNÁNDEZ BUfY, F. (1994): Redes que dan libertad. Introducción a los nuevos movimientos sociales, Barcelona, Paidós.

Rónenas, P. (1991): «Definición de la política\%, en Suplementos Anthropos, 28: 71-80.

- (1994): «Los límites de la política», en Ideas politicas y movimientos sociales, volumen XVII de la Enciclopedia Iberoamericana de Filosofia, Madrid, Trotta, en prensa.

Tocoueville, A. de (1835): La democracia en América, 2 vols., Madrid, Aguilar, 1989.

WALZER, M. (1991): «La idea de sociedad civil. Una vía hacia la reconstmucción de los socials, en Debats, 1992, 39: 30-39.

\footnotetext{
1 Importa destacar aquf que las asociaciones «se distinguen de las organizaciones formales por el hecho de que la finalidad de la asociación aún no se ha independizado funcionalmente de las orientaciones valorativas y de las objetivos de los miembros asociados (J. Habermas, 1993, 47).

2 Para una mayor información acerca de la compusicion del "tercer sector", asi como sobre sus relaciones con el sector estatal y el sector económico, cfr., cntre ofros, R. M. Kramer (1981); U. Ascoli (1987); M. Nerfia (1988 y 1994); J. Cohen y J. Rogern (1992); B. Gidron, R. M. Kramer y L. M. Salamon (1992); $\$$. Kuhnle y P. Scllc (1992).

${ }^{3}$ Redes -como sehalan J. Riechmann y F. Fernảndez Bucy $(1994,14)$ - adonde cooperan personas en una lucha desigual por la supervivencia y la emancipación. Redes, por tanto, que no sirven para apresar, sino que intentan - desde la minima, desesperada, residual esperanza aún posible en nuestro sombrio final de siglo- abrir una perspectiva de libertad y justicia en este sombrio final de siglom.
}

- El asociacionismo cívico - comentan, quizá con excesivo entustasmo, $\mathbf{S}$. Giner y $\$$. Sarasa $(1995,96)$ «satisface los requisitos más estrictos de una ciudadania activa. Articula e integra a los ciudadanos dentro del cuerpo político por medios muy distintos a los de la urna electoral, la manifestación on la plaza pública y los ruegos a los gobernantes. No existen hoy mejor expresión de la ciudadanía genuina que la participación voluntaria de las gentes en el reino de lo público por medio de la acción social altruista".

- Concibo aqui ese espacio o ámbito de xfo púthicow como «un continuo que abarcaria por este orden la socicdad civil no-institucionalizada, las instituciones jurídico-administrativas y la política institucional propiamente dichas (1. Muguerza, 1995, 17)

- Contradictorio porque en ella coexisten y compiten multiples grupos, en ocasioncs de carácter cerrado, con intereses, necesidades y fines trecuentemente opuestos. Pero contradictorio también porque - como señala J. Keane $(1988,33)$ - da socicdad civil no posee 
una inocencia naturats. Ln clla se dan relaciones do opresion sexual, explotación laboral, discriminacion étnica, etcétera.
Tara una introducción a esta particular y compleja problemática tience especial interés algunos tra. bajos de P. Rodenas (1921 y 1994).

\title{
Isonomía, Isegoría, Isomoiría * y democracia a escala global
}

\author{
PHILIP RESNICK \\ Universidad de British Columbia
}

\begin{abstract}
Desde la antigüedad hasta nuestros dias, virtualmente todos los defensores a ultranza de la democracia y del gobierno republicano han subrayado de manera enfática cómo las desigualdades económicas amenazan la democracia.
\end{abstract}

Robert Dahl

Uno de los procesos más sorprendentes de finales del siglo $\mathrm{xx}$ es la tendencia hacia la globalización de la democracia. En Latinoamérica, la transición de autoritarismo a democracia dominó la política durante la década de los ochenta y trajo consigo la restauración de regimenes democráticos a lo largo de todo el cono sur, así como una mayor democratización de la vida política en Centroamérica y México ${ }^{2}$. Desde 1985, con la ascensión de Mijail Gorbachov a la posición de Secretario General del Partido Comunista de la Unión Soviética, los términos glasnost y perestroika se convirtieron en los emblemas de una fase nucva, más democrática, en la Unión Soviética y, por añadidura, cn toda Europa del Este ${ }^{3}$. El modelo marxista-leninista de partido de vanguardia y de sistema de partido-Estado contralizado, comenzó a dejar paso a algo substancialmente más abierto, pluralista y descentralizado en la Unión Soviética misma, en donde se producía una creciente separación entre el Estado y el partido, el centro y las repúblicas de la unión, la sociedad civil y el estado, que se acabarian por convertir en norma. Desde Polonia hasta Bulgaria se producía, a finales de la década de los ochenta, un accleramiento de la historia con el hundimicnto de la mañana a la noche del modelo marxista-leninista. La victoria del movimiento Solidaridad en Polonia, la caída del muro de Berlin y la subsecuente unificacion de las dos Alemanias, la Revolución de Terciopelo checoslovaca, la adhesión de Hungría a la economía de mercado, el violento derrocamiento de Ceaucescu, la sígnificativa erosión del apoyo al comunismo en Bulgaria, Yugoslavia y (ironía de ironías) en la estalinista Albania, todo esto significaba el comienzo de un nuevo capítulo en esa parte del mundo.

Tanto en el sureste asiático como en el sur de Asia se han producido avances, aunque frágiles, hacia la democratizacion: en países como Corea del Sur, Taiwan y Filipinas, así como en Pakistán, Nepal y Bangladesh. Si bien estos avances hacia la democracia se han visto acompañados,

\footnotetext{
* Iraducción de Elvira Bartoso. Una primera versión del presente trabajo fue publicada por Paxis Intemational.
} 